\title{
Trans-thoracic versus trans-hiatal resection for oesophageal carcinoma: a retrospective comparative study of a single-centre case series
}

\author{
Aram Baram ${ }^{1,2^{*}}$ and Hiwa Sherzad ${ }^{3}$
}

\begin{abstract}
Background: Oesophageal carcinoma (EC) is the eighth most common cancer. Surgery is the cornerstone of management for resectable EC. Trans-thoracic oesophagectomy (TTE) and trans-hiatal oesophagectomy (THE) are the two most widely practised procedures. Most of the related controversies are centred on both early and late post-operative complications and mortality (in terms of overall survival and cancer-free survival).

This was a single-centre, retrospective, comparative study analysing the outcomes of two EC resection methods. All 87 patients underwent surgery by the same surgical team over 13 years. Consequently, 87 oesophagectomies with curative intent were performed and divided into the TTE group (group $A=47$ ) and the THE group (group $B=40$ ).

Results: The mean patient age was $65.60 \pm 6.30$ years in the TTE group and $63.48 \pm 9.34$ years in the THE group. No significant difference was found in operative time, blood loss or duration of stay in the intensive care unit. The duration of hospital stay was significantly different between the THE and TTE groups (17.25 \pm 5.92 vs. $12.93 \pm 3.44$, respectively; $P \leq 0.001)$. In-hospital mortality was higher in the TTE group $(9 / 47,19.14 \%)$ than in the THE group (5/ $40,12.5 \%)(P=0.400)$. The mean survival rate from our series showed the superiority of group A (TTE) (65.56 months) over group B (THE) (45.01 months), with $P=0.146$.

Conclusion: No high level of evidence suggests the superiority of one surgical procedure over another. The THE procedure is less time-consuming concerning care and follow-up, and most patients were more satisfied and experienced less pain than with the TTE procedure. Both THE and TTE have comparable post-operative anastomotic complications, and they have no significant long-term survival differences.
\end{abstract}

Keywords: Oesophageal cancer, Surgical resection, Operative approaches, Cancer-free survival, Long-term outcome

\section{Background}

Oesophageal carcinoma (EC) is the eighth most common cancer in the world and is the sixth leading cause of cancer-related mortality worldwide because of its high malignant potential and poor prognosis [1]. The

\footnotetext{
* Correspondence: aram.baramm@gmail.com; aram.baram@univsul.edu.iq 'Department of Surgery, School of Medicine, Faculty of Medical Sciences, University of Sulaimani, François Mitterrand Street, Sulaymaniyah 46001, Iraq ${ }^{2}$ Department of Thoracic and Cardiovascular Surgery, Sulaimani Teaching Hospital, Al Sulaymaniyah, Kurdistan Region 46001, Iraq

Full list of author information is available at the end of the article
}

incidence of EC is expected to increase by approximately $140 \%$ over the next 10 years, faster than any other solid cancer in the world [2]. EC affects more than 500,000 people worldwide annually [3]. The National Cancer Institute in the USA estimates approximately 18,440 new cases and approximately 16,170 deaths from EC in 2020 [4]. EC is four times more common in men than in women [1]. The incidence rate varies internationally by approximately 21-fold [5]; within the highest risk area, the rate is greater than 100 per 100,000 (Asian EC Belt) $[2,6]$. 
Two main histopathological types of EC exist; together, they account for approximately $90 \%$ of all cases of EC: squamous cell carcinoma and adenocarcinoma [7].

Squamous cell carcinoma, the most common type of EC worldwide $[1,2,6]$ and the most common subtype of EC in developing countries [8], evenly affecting the mid and lower oesophagus, has a strong correlation with smoking, alcohol consumption, nutritional deficiencies, chronic inflammation and irritation [2, 9]. Adenocarcinoma is the most common type of EC in Western countries; it has a strong predilection to the lower third of the oesophagus in up to three quarters of cases and is commonly associated with columnar-lined metaplastic epithelium (Barrett's oesophagus), gastroesophageal reflux disease, smoking and obesity [6-9].

Although Helicobacter pylori (H. pylori) is a wellknown risk factor for gastric carcinoma, no significant correlation between $H$. pylori infection and EC has been found in the general population, and it was even found to have a protective effect in oesophageal adenocarcinoma. However, such a correlation was found to be significant in the Middle East [10].

Surgery is the cornerstone of management for earlystage EC $[11,12]$. The most common surgical techniques used to date are trans-thoracic oesophagectomy (TTE) (Ivor Lewis procedure) [13], trans-hiatal oesophagectomy (THE) (Orringer procedure) [14], three-field oesophagectomy (McKeown procedure) [15] and minimally invasive oesophagectomy [16].

While surgical resection is the only treatment modality with curative intent, many researchers have proved that nonsurgical management offers better survival benefits, that oesophagectomy has a relatively high index of mortality and that oesophageal cancer is an incurable disease [2].

Surgery still has a powerful impact on overall survival according to multivariable analyses. The death risk of patients treated with curative surgery is significantly lower than that of patients treated with definite chemoradiotherapy. Furthermore, for patients with stage $\mathrm{T} 3 \mathrm{~N}(+)$ and $\mathrm{T} 4$ disease, surgery combined with neoadjuvant treatment is associated with a significantly higher survival rate than surgery alone or definite chemoradiotherapy [11].

Patients who undergo surgery experience significantly longer survival than those who do not; therefore, curative resection should be considered for oesophageal cancer patients who are medically fit for surgery. Neoadjuvant treatment is recommended for surgically resectable stage T3-T4 EC [11].

A propensity-matched analysis showed that 525 patients who were given preoperative therapy followed by surgery had a median survival duration of 32.3 months compared with 21.9 months in patients who refused surgery. In a multivariate analysis, refusal of surgery remained a strong predictor of poor survival (odds ratio, 1.72; $P<0.001)[2]$.

Trans-thoracic oesophagectomy employs excision of the oesophagus through right thoracotomy under direct vision, excision of the tumour and peritumoural lymphatic tissues combined with mobilization of the stomach through midline laparotomy and reconstruction of the anastomosis in the posterior mediastinum [13]. As the patient undergoes both laparotomy and thoracotomy, there might be more post-operative cardiorespiratory complications, such as mediastinitis and sepsis, and post-operative anastomotic leaks, but this procedure provides more satisfactory oncological clearance of peritumoural tissue and lymph nodes [17-20].

Trans-hiatal oesophagectomy employs dilatation of the oesophageal hiatus through midline laparotomy, dissection of the oesophagus by blunt dissection in the posterior mediastinum without thoracotomy, and then, through a longitudinal left cervical incision, the oesophagus is exposed and gastroesophageal anastomosis is performed in the neck [14]. Therefore, it provides less possibility for compromised post-operative cardiorespiratory function and eliminates the risk of mediastinitis, but the oncological outcome is less favourable because of less oncological clearance [17-20].

Three-stage oesophagectomy (McKeown) combines laparotomy and right thoracotomy with cervical dissection and anastomosis [15]. The potential advantage of this procedure over the other two approaches is more comprehensive lymph node dissection and less need to extend the thoracotomy incision since the anastomosis is in the neck, and it avoids the morbidity associated with intrathoracic anastomosis [21, 22].

In minimally invasive oesophagectomy (MIE), laparoscopy and thoracoscopy are used for intraoperative staging, followed by gastric mobilization and intrathoracic oesophagectomy, respectively. Since it was first introduced by Cuschieri et al. in 1992 [16] as a subtotal endoscopic oesophagectomy through the right thoracoscopic approach, many institutions have reported using this technique in association with either laparotomy or thoracotomy or, more recently, with endoscopy, avoiding open techniques completely [23]. Although the initial results were promising, with a comparable outcome to open resection, avoiding thoracotomy will further reduce pulmonary complications associated with an open approach, and better visual control allows favourable oncological quality of resection. However, there is still no convincing evidence that MIE is superior to open oesophagectomy [24].

Considerable controversies exist about the optimal surgical approach. Most are centred on both early and late post-operative complications and mortality (in terms of overall survival and cancer-free survival). 
Our study aimed to evaluate the differences in both early and late surgical outcomes of the most commonly performed procedures for oesophageal resection in our facility (trans-thoracic versus trans-hiatal oesophagectomy).

\section{Methods}

\section{Study design}

This was a single-centre, retrospective, comparative, observational study analysing the outcomes of the two most common methods of EC resection (trans-thoracic versus trans-hiatal oesophagectomy). Patients with retrospective data were included and analysed prospectively. This manuscript has been reported in line with the Strengthening the Reporting of Cohort Studies in Surgery (STROCSS) statement [25].

\section{Setting}

This study was conducted in a single academic institution. Between February 2007 and February 2020, 87 oesophageal resections with curative intent were included: TTE (group A = 47) and THE (group B = 40).

All the data were obtained directly from the patients, patients' relatives and medical records. Approval was granted from the Ethical and Scientific Council of our institution. This study was registered at ResearchRegistry.com (researchregistry5755).

Patient characteristics, including demographic data (Table 1), comorbidities, preoperative imaging data (barium swallow, abdominal ultrasound (US) and computed tomography (CT) of the chest and abdomen), cardiorespiratory function (pulmonary function test (PFT), echocardiography and chest radiography) and endoscopic variables from both oesophagogastroduodenoscopy (EGD) and endoscopic ultrasound (EUS), were analysed. As in the beginning of the study positron emission tomography-computed tomography (PET-CT) was not available, we depended on chest CT and EUS findings for the purpose of preoperative clinical staging.

All patients underwent a histopathological examination for EC of the mid and lower oesophagus. Patients with distant metastases were excluded. Patients were staged according to the 8th edition of the TNM (tumour, node and metastasis) staging system.

Operative details, technique, safety margins, type of anastomosis, duration, intraoperative complications and blood loss were analysed.

Post-operative follow-up, intensive care unit stay, total hospital stay and any post-operative complications (wound infection, anastomotic leak and vocal cord paralysis) were recorded. Patients were followed up at regular intervals with an operative consultant every month for up to 3 months, then every 3 months for up to 1 year and then every 6 months for up to 5 years.

\section{Surgical procedures}

Patients were thoroughly discussed at multidisciplinary meetings, and decisions regarding the surgical approach were made by the operating surgeon according to his experience and comfortability with the operative approach

Table 1 Patient characteristics

\begin{tabular}{|c|c|c|c|c|}
\hline \multirow[t]{2}{*}{ Variables } & \multirow[t]{2}{*}{ Category } & \multirow{2}{*}{$\begin{array}{l}\text { Group A (TTE) } \\
n(\%) 47,(54.02 \%)\end{array}$} & \multirow{2}{*}{$\begin{array}{l}\text { Group B (THE) } \\
n(\%) 40,(45.97 \%)\end{array}$} & \multirow{2}{*}{$\begin{array}{l}P \\
\text { value }\end{array}$} \\
\hline & & & & \\
\hline Age (Mean \pm SD) & Year & $65.60 \pm 6.30$ & $63.48 \pm 9 / 34$ & 0.212 \\
\hline \multirow[t]{4}{*}{ Age group } & $40-50$ & $1(2.1 \%)$ & $5(12.5 \%)$ & \\
\hline & $51-60$ & $9(19.1 \%)$ & 7 (17.5\%) & \\
\hline & $61-70$ & $29(61.7 \%)$ & $24(60 \%)$ & \\
\hline & $71-80$ & $8(17 \%)$ & $4(10 \%)$ & \\
\hline \multirow[t]{2}{*}{ Gender } & Male & $30(63.8 \%)$ & $27(67.5 \%)$ & 0.720 \\
\hline & Female & $17(36.2 \%)$ & $13(32.5 \%)$ & \\
\hline Smoking & & $26(55.3 \%)$ & $24(60 \%)$ & 0.660 \\
\hline \multirow[t]{4}{*}{ Comorbidities } & DM & 19 (40.4\%) & $11(27.5 \%)$ & 0.206 \\
\hline & HTN & 41 (87.2\%) & $31(77.5 \%)$ & 0.231 \\
\hline & $\mathrm{IHD}$ & 25 (53.2\%) & 27 (67.5\%) & 0.175 \\
\hline & COAD & $8(17 \%)$ & $14(35 \%)$ & $0.055+$ \\
\hline \multirow[t]{3}{*}{ Clinical stages } & । & $3(6.4 \%)$ & $1(2.5 \%)$ & 0.489 \\
\hline & $\|$ & $20(42.5 \%)$ & $13(32.5 \%)$ & \\
\hline & III & $24(51.0 \%)$ & $26(65.0 \%)$ & \\
\hline \multirow[t]{2}{*}{ Histology } & SCC & 35 (74.4\%) & $24(60 \%)$ & 0.529 \\
\hline & Adenocarcinoma & $12(25.5 \%)$ & $16(40 \%)$ & \\
\hline
\end{tabular}


and patient characteristics (tumour stage, level and comorbidities).

In group A (47 patients), standard trans-thoracic oesophagectomy (Ivor Lewis operation) was performed. In group B (40 patients), standard trans-hiatal oesophagectomy (Orringer procedure) was performed. Standard gastric tubes were used in both groups. All gastroesophageal anastomoses were hand-sewn with a single layer of interrupted absorbable Vicryl (Ethicon Inc., USA). A stapler was not used for the anastomosis of suture lines in this series. No gastric drainage procedure was performed. Finally, a standard feeding jejunostomy tube was inserted into group A patients only. An intercostal drain was inserted into all patients in group A and inserted into select patients in group B. Cervical and abdominal wounds were always drained and closed with standard methods.

\section{Post-operative care}

All efforts were made to wean the patient from mechanical ventilation in the immediate post-operative period. All the patients remained in the intensive care unit for a minimum of $24 \mathrm{~h}$ and were transferred to the conventional surgical ward accordingly. In cases of failed extubation, a further extubation attempt was made within the subsequent days. Enteral feeding started through the jejunostomy tube on the second or third post-operative day in group A and through the nasoentric tube in group B. Post-operative respiratory physiotherapy was encouraged in the form of incentive spirometry and early mobilization.

Patients were kept nil by mouth for at least 7 days. On the 8th post-operative day, if there were no clinical or radiological signs of a leak, then a liquid diet was allowed within the following days, while a cervical drain was kept in place.

\section{Statistical analysis}

The data were collected and entered into an Excel sheet; after coding, they were transferred to Statistical Package for the Social Sciences (SPSS), version 22. IBM Corporation and $\mathrm{R}$ environment version 3.2.2 were used for data analysis. Descriptive and quantitative analyses were performed. The relationships between the initial findings and subsequent morbidity and mortality were determined using the chi-square test or Fisher's exact test for nominal variables and Student's $t$ test for quantitative variables. A $P$ value $\leq 0.05$ was considered significant. Kaplan-Meier survival curves were used to estimate tumour-free survival.

\section{Results}

A total of 87 patients underwent oesophagectomy for oesophageal cancer. Patients were grouped into group A (47 patients (54.02\%) TTE) and group B (40 patients
(45.97\%) THE). Demographic details of both groups are shown in Table 1. Overall, there were no significant differences in demographic characteristics between the groups. The mean patient age was $65.60 \pm 6.30$ years in the TTE group and $63.48 \pm 9.34$ years in the THE group.

Male patients predominated in both groups. Chronic obstructive airway disease (COAD) was the most common associated comorbidity in group B (35\%) (vs. 17\% in group A; $P=0.055+$ ). The most common clinical presentations were dysphagia (solid (96.6\%) and liquid (89.7\%)) and anorexia $(62.1 \%)$. The majority of our patients were in stages II (37.9\%) and III (57.4\%). Three patients from group A had a lymph node (LN) status of N2 and received neoadjuvant chemotherapy (Tables 1, 2 and 3).

The operative details and post-operative courses are shown in Table 4. Differences in operative time, total blood loss during the operation and number of hours of stay in the intensive care unit post-operatively were not significant between the groups. There was a statistically significant difference in the duration of hospital stay postoperatively among patients who received THE vs. TTE $(17.25 \pm 5.92$ vs $12.93 \pm 3.44$, respectively) $(P \leq 0.001)$.

Detailed post-operative complications are shown in Table 5. Hypokalaemia was the most common postoperative complication among TTE patients (57.4\%) (versus $22.5 \%$ among THE patients; $P=0.001$ ). Although statistically non-significant, we found more anastomotic leaks in the THE group $(10 / 40(27.5 \%))$ than in the TTE group $(11 / 47(21.2 \%))(P=0.499)$. Re-operation was necessary in three patients who received TTE, and the stent was covered in the remainder of patients (7 patients), while 7 patients who received THE were treated conservatively with a T-tube and cervical wound care, and reoperation was performed in four patients. Vocal cord paralysis was noted in 3 patients in the THE group (7.5\%) but not in any patient in the TTE group $(P=0.093)$.

In-hospital mortality was higher in the TTE group $(9 /$ $47,19.14 \%)$ than in the THE group $(5 / 40,12.5 \%)(P=$ 0.400 ). Leak was the cause of death (mediastinitis-related sepsis) in $5 / 9$ patients in the TTE group and in $3 / 5$

Table 2 Clinical stage distribution in two groups of patients studied

\begin{tabular}{lllll}
\hline Tumour stage & Group A & Group B & Total & $P$ value \\
\hline T1N0M0 & $3(6.4 \%)$ & $1(2.5 \%)$ & $4(4.6 \%)$ & 0.621 \\
T2N0M0 & $3(6.4 \%)$ & $2(5.0 \%)$ & $5(5.7 \%)$ & 1.000 \\
T2N1M0 & $9(19.1 \%)$ & $12(30.0 \%)$ & $21(24.1 \%)$ & 0.238 \\
T2N2M0 & $1(2.1 \%)$ & $0(0 \%)$ & $1(1.1 \%)$ & 1.000 \\
T3N0M0 & $12(25.5 \%)$ & $8(20.0 \%)$ & $20(22.9 \%)$ & 0.541 \\
T3N1M0 & $17(36.2 \%)$ & $17(42.5 \%)$ & $34(39.1 \%)$ & 0.546 \\
T3N2M0 & $2(4.3 \%)$ & $0(0 \%)$ & $2(2.3 \%)$ & 0.497 \\
Total & $47(100 \%)$ & $40(100 \%)$ & $87(100 \%)$ & - \\
\hline$P=0.557$, & & &
\end{tabular}

$P=0.557$, not significant, Chi-square test 
Table 3 Clinical stage distribution in two groups of patients studied

\begin{tabular}{lllll}
\hline Clinical stage & Group A & Group B & Total & $\boldsymbol{P}$ value \\
\hline Stage I & $3(6.4 \%)$ & $1(2.5 \%)$ & $4(4.6 \%)$ & 0.621 \\
Stage II & $10(21.3 \%)$ & $8(20.0 \%)$ & $18(20.7 \%)$ & 0.884 \\
Stage IIB & $10(21.3 \%)$ & $5(12.5 \%)$ & $15(17.3 \%)$ & 0.280 \\
Stage III & $23(48.9 \%)$ & $26(65.0 \%)$ & $49(56.3 \%)$ & 0.132 \\
Stage IIIB & $1(2.1 \%)$ & 0 & $1(1.1 \%)$ & 1.000 \\
Total & $47(100 \%)$ & $40(100 \%)$ & $87(100 \%)$ & - \\
\hline
\end{tabular}

$P=0.489$, not significant, Fisher exact test

patients in the THE group. Respiratory failure and inability to wean from a ventilator caused death in one patient in the TTE group (2.12\%), while in the THE group, pulmonary complications (respiratory failure) were encountered in two patients (5\%); one was a consequence of post-operative leaks $(P=0.592)$. Cardiac complications were noted in $4(8.5 \%)$ patients in the TTE group, three of whom had acute myocardial infarction with sudden cardiac arrest and one who developed acute rapid atrial fibrillation (AF) and was treated medically with anti-arrhythmic medications. In the THE group, cardiac complications were noted in 2 patients (5\%) (one with sudden cardiac arrest and another with rapid AF who was treated medically; $P=0.683$ ).

Post-operative dysphagia was noted in both the TTE (7 $(14.89 \%))$ and THE $(8(20 \%))$ groups $(P=0.530)$. The tumour recurrence rate was not different between the groups (TTE $3 / 47$ vs. THE $6 / 40, P=0.291$ ).

The estimated survival duration from our series showed that the mean survival duration was longer in group A (TTE) (65.56 months) than in group B (THE) (45.01 months), with $P=0.146$ (Fig. 1).

\section{Discussion}

The exact incidence of EC in our locality (Iraqi Kurdistan) is unknown due to the lack of a national cancer registry; therefore, there is a strong need to perform research on different types of cancer in our region. The most credible published data from our single-province cancer registry (Hiwa Hospital) over 8 years of observation (2006-2014) showed that the age-specific incidence of EC is approximately 18.77 for males and 13.18 for females/100,000 population/year for those aged older than 65 years [26]. This high rate of incidence is expected, as Iraqi Kurdistan is included within the Asian Esophageal Cancer Belt [26].

EC is a highly aggressive tumour; half of the patients present later with distant metastasis, and only $30-40 \%$ of patients are operable at the time of presentation [1, $12]$. Surgery is the cornerstone of management for resectable EC $[11,12]$. There is no high level of evidence to suggest the superiority of one surgical procedure over another; most of the observations have been from individual studies and small-sample randomized controlled trials. Each surgical approach has its own pros and cons: some advocate TTE for oncological perspective only, while others advocate THE, as it is associated with relatively less early morbidity and mortality. The decision regarding surgical technique is based mostly on the experience of the surgeon and hospital, comorbidities, level and stage of the oesophageal tumour [11, 27]. The choice of approach was surgeon preference guided mainly by nodal staging, MDT, tumour size and extend. The surgical approach for each patient was thoroughly discussed at the multidisciplinary meetings, and decision regarding surgical approach was made by the operating surgeon according to his experience and comfort ability with the operative approach and patients characteristics (tumour stage, level, mediastinal nodal status and comorbidities)

In our series, there was no statistically significant difference between the groups at baseline in terms of demographic or tumour characteristics; however, the rate of COAD was higher in group B (35\%) than in group A $(17 \% ; P=0.055+)$. This higher number of COAD patients in the THE group can be explained by the fact that TTE is associated with higher postoperative cardiorespiratory compromise; therefore, selecting these high-risk patients for THE might eliminate or decrease post-operative respiratory complications [28].

Hulscher et al. [19] conducted a randomized controlled trial that reached level I of evidence regarding the best surgical treatment for EC. THE was associated with a shorter operative duration ( 3.5 vs. $6 \mathrm{~h}$ ), less blood loss ( 1 vs. 1.9 litters), a lower perioperative morbidity

Table 4 Operative details and post-operative course

\begin{tabular}{|c|c|c|c|}
\hline & Group A (TTE) & Group B (THE) & $P$ \\
\hline & $n(\%), 47(54.02 \%)$ & $n(\%), 40$ (45.97\%) & \\
\hline Duration of surgery (min) & $172.77 \pm 35,67$ & $178.48 \pm 36.14$ & 0.462 \\
\hline Blood loss (ml) & $619.15 \pm 175.25$ & $587.5 \pm 234.45$ & 0.474 \\
\hline Intraoperative complications & $20(42.6 \%)$ & $10(25 \%)$ & 0.086 \\
\hline ICU stay (h) & $28.51 \pm 11.93$ & $30.13 \pm 15.86$ & 0.590 \\
\hline Hospital stay (days) & $12.93 \pm 3.44$ & $17.25 \pm 5.92$ & $<0.001$ \\
\hline
\end{tabular}


Table 5 Post-operative complications

\begin{tabular}{llll}
\hline Complications & TTE & THE & $\begin{array}{l}\boldsymbol{P} \\
\text { value }\end{array}$ \\
\hline Hypokalaemia & $\boldsymbol{n}(\mathbf{\%}) \mathbf{4 7}(\mathbf{5 4 . 0 2} \%)$ & $\boldsymbol{n}(\mathbf{\% )}, \mathbf{4 0}(\mathbf{4 5 . 9 7 \% )}$ & $9(22.5 \%)$ \\
Wound infection & $27(57.4 \%)$ & $18(45 \%)$ & 0.001 \\
Anastomotic leak & $20(42.5 \%)$ & $11(27.5 \%)$ & 0.819 \\
Pulmonary complications & $10(21.2 \%)$ & $2(5 \%)$ & 0.499 \\
Cardiac complications & $1(2.12 \%)$ & $2(5 \%)$ & 0.592 \\
Vocal cord paralysis & $4(8.5 \%)$ & $3(7.5 \%)$ & 0.683 \\
In-hospital mortality & $0(0 \%)$ & $5(12.5 \%)$ & 0.093 \\
Post-operative dysphagia & $9(19.14 \%)$ & $8(20 \%)$ & 0.400 \\
Tumour recurrence & $7(14.89 \%)$ & $6(15 \%)$ & 0.530 \\
\hline
\end{tabular}

rate (pulmonary complications $27 \%$ vs. 57\%, chylous leakage $2 \%$ vs. $10 \%$ ) and shorter hospital stay (mean 15 days vs. 19 days, $P \leq 0.001$ ) than TTE. Within our series, we did not identify a statistically significant difference in operative time $(172.77 \pm 35.67$ vs. $178.48 \pm 36.14$, respectively; $P=0.462)$, blood loss $(619.15 \pm 175.25$ vs $587.5 \pm 234.45$, respectively; $P=0.474$ ), perioperative morbidity such as pulmonary complications $(2.12 \%$ vs. $5 \%$, respectively; $P=0.592$ ) or cardiac complications ( $8.5 \%$ vs. $5 \%$, respectively; $P=0.683 \%$ ), between the TTE and THE groups. Chylous leakage was not observed in either group. We observed higher respiratory complications in the THE group, although the difference was not statistically significant, but we found that COAD (in the THE group) was associated with other systemic diseases, especially cardiovascular diseases such as ischaemic heart disease and hypertension.

Early post-operative complications, such as hypokalaemia, were observed more often in the TTE group than in the THE group (57.4 vs. $22.5 \%$, respectively; $P=$ 0.001). These later post-operative complications were not reported by many authors; in our case, the possible explanation could be insufficient replacement or loss from the jejunostomy feeding tube we used for group A patients [29]. Concerning in-hospital mortality, although the difference was not statistically significant, the

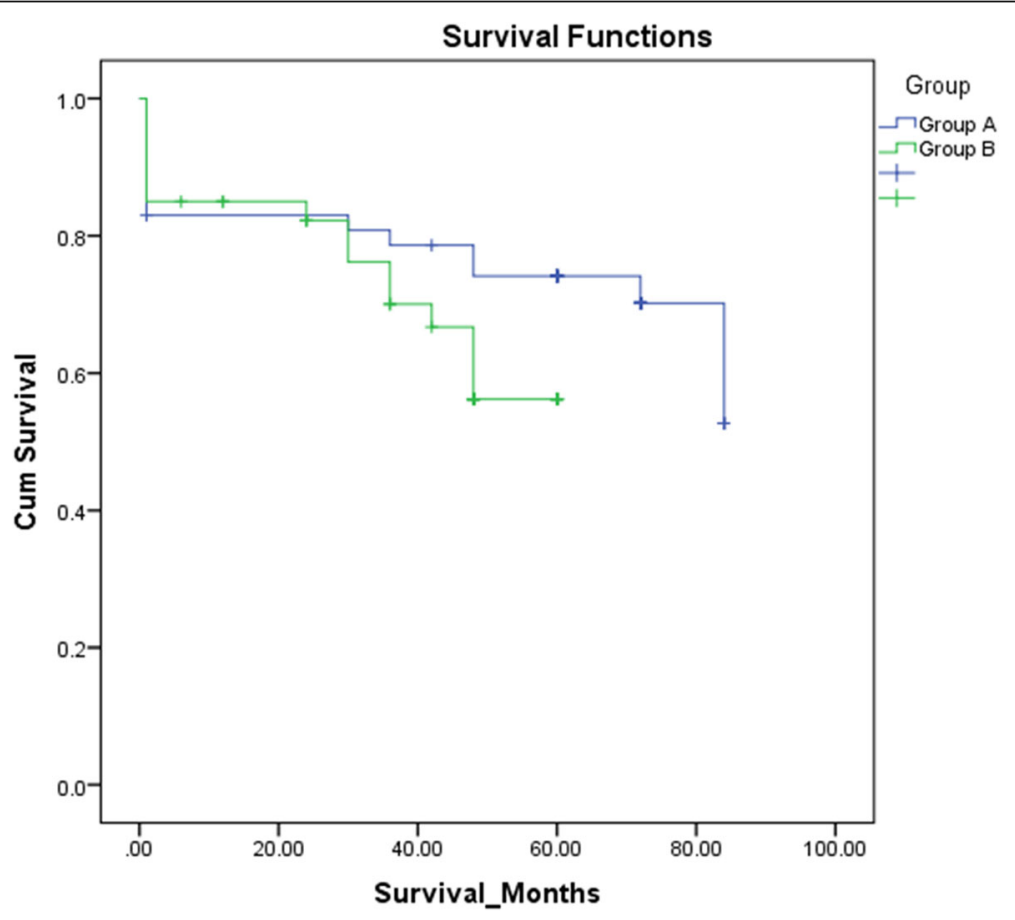

Fig. 1 Kaplan-Meier survival curve shows 5-year survival in both the TTE (group A) and THE (group B) groups 
mortality rate was higher in the TTE group (19.14\%) than in the THE group $(12.5 \%)(P=0400)$. Of those patients, 5/9 had anastomotic leak-related sepsis, three died from sudden cardiac arrest (acute myocardial infarction) and one died from respiratory failure. The higher complication rate in the TTE group has been well explained in the literature: a leak in the chest is associated with more severe clinical outcomes, such as mediastinitis and sepsis [28].

Patients who received TTE had a shorter hospital stay than patients who received THE $(12.93 \pm 3.44$ vs. 17.25 \pm 5.92 , respectively; $P \leq 0.001$ ). We correlated the longer hospital stay of the THE group in our series with anastomotic leaks, although the leak rate was comparable in our series. In contrast, post-operative leaks after TTE was associated with a more severe clinical course and longer hospital stay. However, in our series, leaks after TTE were managed with a covered stent $(7 / 10)$, while early post-operative leaks were treated with reoperation. Leaks after THE were treated conservatively (7/11) with the controlled fistula technique, opening of the cervical wound and packing and daily dressing rather than with a stent because of the unavailability of a conventional stent at the cervical location [30].

Gooszen et al. [31] compared the surgical approach and predictors of post-operative anastomotic leaks. The anastomotic leak rate was $19.6 \%$. They found a lower rate of anastomotic leaks with TTE (17.0\%) than with THE (21.9) $(P=0.025)$ and that independent predictors of anastomotic leaks were ASA fitness grades III and IV, $\mathrm{DM}, \mathrm{COAD}$, history of cardiac arrhythmia and proximal location of the tumour. In our series, the leak rate was 24.1\%. Although statistically non-significant, patients who received TTE had a lower rate of leaks than those who received THE $(21.3 \%$ vs. $27.5 \%$, respectively; $P=$ $0.499)$. We could not find such a relation between these variables and the leak rate in our series.

The higher rate of leaks with THE can been explained, as the reconstruction of a long gastric conduit and narrow thoracic inlet can compromise the vascularity of the conduit, with subsequent ischaemia and venous congestion, necrosis and disruption of the anastomosis [32, 33]. Despite a lower leak rate and shorter hospital stay with TTE, some surgeons (including us) believe that THE with cervical anastomosis will allow a wider resection margin of the oesophagus and less severe post-operative complications [31, 34].

The left recurrent laryngeal nerve (LRLN) paresis rate in our series was $7.5 \%$ (TTE $0 \%$ vs. THE $7.5 \%, P=$ 0.095). This higher rate of RLN paresis after THE indicates that RLN is mainly at risk during cervical dissection and reconstruction of the anastomosis. The rate found in our study is comparable to that reported by Gooszen et al. (7.0\%) [32] but lower than that reported by Rindani et al. (11.2\%) [33], Hulscher et al. (13\%) [19] and Liu et al. (10.3\%) [35]. All observed that THE was associated with a higher incidence of LRLN paresis.

Post-operative anastomotic stricture with subsequent dysphagia was observed in $14.89 \%$ of patients in the TTE group and $20 \%$ of patients in the THE group $(P=$ $0.530)$. Three of seven patients $(42.8 \%)$ in the TTE group and 5/8 (62.5\%) in the THE group required one or more sessions of endoscopic dilatation. None of our patients required surgical intervention. This higher rate of anastomotic stricture associated with THE has also been reported by other studies. Boshier et al. [11] conducted a meta-analysis and found a stricture rate of $25.1 \%$ among patients in the THE group versus $21.8 \%$ among patients in the TTE group. Rindani et al. [35] found a stricture rate of $28 \%$ among patients in the THE group vs. $16 \%$ among patients in the TTE group and Liu et al. found a stricture rate of $19.8 \%$ among patients in the THE group vs. $13.5 \%$ among patients in the TTE group [35]. Gastric conduit ischaemia with subsequent post-operative anastomotic leaks, stapled anastomosis, cardiovascular diseases and COAD were identified as risk factors [24, 31, 33, 36, 37].

The patterns of tumour recurrence were as follows: 3 patients $(6.38 \%)$ in the TTE group experienced recurrence ( 2 local and 1 distant) and 6 patients (15\%) in the THE group experienced recurrence (5 local and 1 distant $)(P=0.291)$. Although statistically non-significant in our series, this higher rate of recurrence has been reported in the literature and is the point of controversy among authors. Some believe that TTE allows better access to the posterior mediastinum, with extended en bloc dissection of all peritumoural tissue and lymphadenectomy, hence reducing the rate of loco-regional recurrence [19], while others consider mediastinal lymph node involvement as systemic micro-metastatic disease and, thus, extended resection will not change the outcome $[38,39]$.

Colvin et al. conducted a meta-analysis from 1950 to 2010 (five randomized controlled trials and one metaanalysis) and concluded that TTE may offer a superior 5 -year survival rate in patients with limited positive lymph nodes. However, other authors reported no significant difference (Boshier et al.: TTE 26.6\% versus THE 25.8, $P=0.84$ [11]; Kawoosa et al.: TTE 32.76\% versus THE $30.24 \%, P=0.596$ [39]; and Rindani et al.: TTE 26\% versus THE 24\% [33]). The Kaplan-Meier survival curve (Fig. 1) shows 5-year survival in both the TTE and THE groups. The mean survival duration was higher in group A (TTE) (65.56 months) than in group B (THE) (45.01 months), with $P=0.146$ (log-rank test).

Overall, there is no high level of evidence to date to demonstrate the superiority of one surgical approach over another, and there are several concerns and 
advantages with each surgical approach (TTE and THE) that remain controversial. The decision to perform oesophagectomy with either technique depends on the preference and experience of the operating surgeon and baseline physiological characteristics such as comorbidities and level and stage of the tumour [40, 41].

Our study was conducted on a relatively small sample and was non-randomized. The duration of follow-up was relatively acceptable for most patients. A larger study with randomization is required for a stronger level of evidence.

\section{Conclusions}

Oesophageal carcinoma is a rapidly increasing cancer worldwide, with a distinct geographical distribution. Surgery remains the cornerstone for curative treatment in the early stages of oesophageal carcinoma, although long-term survival is poor. Considerable debate exists over the best surgical approach based on perioperative morbidity and mortality and long-term survival. Transhiatal oesophagectomy is associated with a longer hospital stay, a higher rate of respiratory complications, post-operative anastomotic leaks, recurrent laryngeal nerve injury, post-operative strictures, subsequent dysphagia and recurrence. Long-term survival is higher with TTE.

\section{Abbreviations}

EC: Oesophageal carcinoma; TTE: Trans-thoracic oesophagectomy; THE: Trans-hiatal oesophagectomy; MIE: Minimally invasive oesophagectomy; STROCSS: Strengthening the Reporting of Cohort Studies in Surgery; US: Ultrasound; CT: Computed tomography; PFT: Pulmonary function test; EGD: Oesophagogastroduodenoscopy; EUS: Endoscopic ultrasound; TNM: Tumour, node and metastasis; SPSS: Statistical Package for the Social Sciences; COAD: Chronic obstructive airway disease; LN: Lymph node: AF: Atrial fibrillation; LRLN: Left recurrent laryngeal nerve paresis

\section{Acknowledgements}

We would like to acknowledge all our personnel who assisted in serving our patients.

\section{Authors' contributions}

All authors have read and approved the manuscript. AB: Surgeon in charge, study design, follow-up, data collection, manuscript revision and statistical analysis. HS: Assisted in surgeries, follow-up, study design, data collection and drafting

\section{Funding}

This research did not receive any specific grant from any funding agency in the public, commercial or not-for-profit sectors.

\section{Availability of data and materials}

All our raw data available upon request

\section{Ethics approval and consent to participate}

This study was approved by our institution (Kurdistan Board for Medical Specialization) ethics committee (approval number 2045 in 28 November 2019). Verbal and written consent obtained from all patients for anonymous data publication.

\section{Consent for publication}

A written consent for anonymous publication of the data obtained from all of the patients; any liable photography or radiography image was permitted to be published anonymously.

\section{Competing interests}

No conflict of interest associated with this draft

\section{Author details}

${ }^{1}$ Department of Surgery, School of Medicine, Faculty of Medical Sciences, University of Sulaimani, François Mitterrand Street, Sulaymaniyah 46001, Iraq. ${ }^{2}$ Department of Thoracic and Cardiovascular Surgery, Sulaimani Teaching Hospital, Al Sulaymaniyah, Kurdistan Region 46001, Iraq. ${ }^{3}$ Kurdistan Board for Medical Specialization/Cardiothoracic and Vascular Surgery, Sulaimani DOH, Al Sulaymaniyah, Kurdistan Region, Iraq.

Received: 20 July 2020 Accepted: 10 November 2020

Published online: 25 November 2020

\section{References}

1. Zhang Y (2013) Epidemiology of esophageal cancer. World J Gastroenterol 19(34):5598-5606. https://doi.org/10.3748/wjg.v19.i34.5598

2. Napier KJ, Scheerer M, Misra S (2014) Esophageal cancer: a review of epidemiology, pathogenesis, staging workup and treatment modalities. World J Gastrointest Oncol 6(5):112-120. https://doi.org/10.4251/wjgo.v6.i5. 112

3. Bray F, Ferlay J, Soerjomataram I, Siegel RL, Torre LA, Jemal A (2018) Global cancer statistics 2018: GLOBOCAN estimates of incidence and mortality worldwide for 36 cancers in 185 countries. CA Cancer J Clin 68(6):394-424. https://doi.org/10.3322/caac.21492

4. Siegel RL, Miller KD, Jemal A (2020) Cancer statistics, 2020. CA A Cancer J Clin 70:7-30. https://doi.org/10.3322/caac.21590

5. Torre LA, Bray F, Siegel RL, Ferlay J, Lortet-Tieulent J, Jemal A (2015) Global cancer statistics, 2012. CA Cancer J Clin 65(2):87-108. https://doi.org/10. 3322/caac.21262

6. Pennathur A, Gibson MK, Jobe BA, Luketich JD (2013) Oesophageal carcinoma. Lancet 381(9864):400-412. https://doi.org/10.1016/501406736(12)60643-6

7. Klingelhöfer D, Zhu Y, Braun M et al (2019) A world map of esophagus cancer research: a critical accounting. J Transl Med 17:150. https://doi.org/ 10.1186/s12967-019-1902-7

8. Arnold M, Soerjomataram I, Ferlay J, Forman D (2015) Global incidence of oesophageal cancer by histological subtype in 2012. Gut. 64(3):381-387. https://doi.org/10.1136/gutjnl-2014-308124

9. Enzinger PC, Mayer RJ (2003) Esophageal cancer. N Engl J Med 349(23): 2241-2252. https://doi.org/10.1056/NEJMra035010

10. Gao H, Li L, Zhang C et al (2019) Systematic review with meta-analysis: association of Helicobacter pylori infection with esophageal cancer. Gastroenterol Res Pract 2019:1953497. https://doi.org/10.1155/2019/1953497

11. Boshier PR, Anderson O, Hanna GB et al (2011) Ann Surg 254(6):894-906. https://doi.org/10.1097/SLA.0b013e3182263781

12. Chang AC, Ji H, Birkmeyer NJ, Orringer MB, Birkmeyer JD (2008) Outcomes after transhiatal and transthoracic esophagectomy for cancer. Ann Thorac Surg 85(2):424-429. https://doi.org/10.1016/j.athoracsur.2007.10.007

13. Ewis I (1946) The surgical treatment of carcinoma of the oesophagus; with special reference to a new operation for growths of the middle third. $\mathrm{Br} J$ Surg 34:18-31. https://doi.org/10.1002/bjs.18003413304

14. Orringer MB, Sloan H. Esophagectomy without thoracotomy. J Thorac Cardiovasc Surg. 1978;76(5):643-654.

15. McKeown KC. Trends in oesophageal resection for carcinoma with special reference to total oesophagectomy. Ann R Coll Surg Engl. 1972;51(4):213239. PMID 5083864

16. Cuschieri A, Shimi S, Banting S. Endoscopic oesophagectomy through a right thoracoscopic approach. Journal of the Royal College of Surgeons of Edinburgh. 1992 Feb;37(1):7-11. PMID 1573620

17. Colvin H, Dunning J, Khan OA (2011) Transthoracic versus transhiatal esophagectomy for distal esophageal cancer: which is superior? Interact Cardiovasc Thorac Surg 12(2):265-269. https://doi.org/10.1510/icvts.2010. 252148 
18. Yang K, Chen HN, Chen XZ et al (2012) Transthoracic resection versus nontransthoracic resection for gastroesophageal junction cancer: a metaanalysis. PLoS One 7(6):e37698. https://doi.org/10.1371/journal.pone.0037698

19. Hulscher JB, van Sandick JW, de Boer AG et al (2002) Extended transthoracic resection compared with limited transhiatal resection for adenocarcinoma of the esophagus. N Engl J Med 347(21):1662-1669. https://doi.org/10.1056/ nejmoa022343

20. Hulscher JB, Tijssen JG, Obertop H, van Lanschot JJ (2001) Transthoracic versus transhiatal resection for carcinoma of the esophagus: a meta-analysis. Ann Thorac Surg 72(1):306-313. https://doi.org/10.1016/s00034975(00)02570-4

21. Patel S, Petrov R, Abbas A, Bakhos C. Robotic-assisted McKeown esophagectomy. J Vis Surg. 2019;5:43. doi https://doi.org/10.21037/jovs.2019. 03.14

22. D'Amico TA. Mckeown esophagogastrectomy. J Thorac Dis. 2014;6 Supp 3(Suppl 3):S322-S324. doi https://doi.org/10.3978/j.issn.2072-1439.2014.03.28

23. Smithers BM (2010) Minimally invasive esophagectomy: an overview. Expert Rev Gastroenterol Hepatol 4(1):91-99. https://doi.org/10.1586/egh.09.62

24. McK Manson J, Beasley WD (2014) A personal perspective on controversies in the surgical management of oesophageal cancer. Ann R Coll Surg Engl 96(8):575-578. https://doi.org/10.1308/003588414x13946184901605

25. Agha R, Abdall-Razak A, Crossley E, Dowlut N, losifidis C, Mathew G, for the STROCSS Group (2019) The STROCSS 2019 Guideline: Strengthening the Reporting of Cohort Studies in Surgery. Int J Surg. 72:156-65. https://doi. org/10.1016/j.ijsu.2019.11.002. Epub 2019 Nov 6.

26. Khoshnaw N, Mohammed HA, Abdullah DA (2015) Patterns of cancer in Kurdistan - results of eight years cancer registration in Sulaymaniyah Province-Kurdistan-Iraq. Asian Pac J Cancer Prev 16(18):8525-8531. https:// doi.org/10.7314/apjcp.2015.16.18.8525

27. Decker G, Coosemans W, De Leyn P et al (2009) Minimally invasive esophagectomy for cancer. Eur J Cardiothorac Surg 35(1):13-21. https://doi. org/10.1016/j.ejcts.2008.09.024

28. Barreto JC, Posner MC (2010) Transhiatal versus transthoracic esophagectomy for esophageal cancer. World J Gastroenterol 16(30):38043810. https://doi.org/10.3748/wjg.v16.i30.3804

29. Mitchell H (2014 Jan) Rosner, Alan C Dalkin. Electrolyte disorders associated with cancer. Adv Chronic Kidney Dis 21(1):7-17. https://doi.org/10.1053/j. ackd.2013.05.005

30. Wu G, Yin M, Zhao YS et al (2017) Novel esophageal stent for treatment of cervical anastomotic leakage after esophagectomy. Surg Endosc 31(12): 5024-5031. https://doi.org/10.1007/s00464-017-5545-6

31. Gooszen JAH, Goense L, Gisbertz SS, Ruurda JP, van Hillegersberg R, van Berge Henegouwen MI (2018) Intrathoracic versus cervical anastomosis and predictors of anastomotic leakage after oesophagectomy for cancer. $\mathrm{Br} J$ Surg 105(5):552-560. https://doi.org/10.1002/bjs.10728

32. Jauch KW, Bacha EA, Denecke H, Anthuber M, Schildberg FW. Esophageal carcinoma: prognostic features and comparison between blunt transhiatal dissection and transthoracic resection. Eur J Surg Oncol. 1992;18(6):553-562. PMID 1478287

33. Urschel JD. Esophagogastrostomy anastomotic leaks complicating esophagectomy: a review. Am J Surg. 1995;169(6):634-640.doi https://doi. org/10.1016/s0002-9610(99)80238-4

34. Blewett CJ, Miller JD, Young JE, Bennett WF, Urschel JD. Anastomotic leaks after esophagectomy for esophageal cancer: a comparison of thoracic and cervical anastomoses. Ann Thorac Cardiovasc Surg. 2001;7(2):75-78.PMID 11371275

35. Rindani R, Martin CJ, Cox MR. Transhiatal versus Ivor-Lewis oesophagectomy: is there a difference?. Aust N Z J Surg. 1999;69(3):187-194. doi https://doi.org/10.1046/j.1440-1622.1999.01520.x

36. Law S, Fok M, Chu KM, Wong J (1997) Comparison of hand-sewn and stapled esophagogastric anastomosis after esophageal resection for cancer: a prospective randomized controlled trial. Ann Surg 226(2):169-173. https:// doi.org/10.1097/00000658-199708000-00008

37. van Heijl M, Gooszen JA, Fockens P, Busch OR, van Lanschot JJ, van Berge Henegouwen MI (2010) Risk factors for development of benign cervical strictures after esophagectomy. Ann Surg 251(6):1064-1069. https://doi.org/ 10.1097/sla.0b013e3181deb4b7

38. Davies AR, Forshaw MJ, Khan AA et al (2008) Transhiatal esophagectomy in a high volume institution. World J Surg Oncol 6:88. https://doi.org/10.1186/ 1477-7819-6-88

39. Kawoosa NU, Dar AM, Sharma ML et al (2011) Transthoracic versus transhiatal esophagectomy for esophageal carcinoma: experience from a single tertiary care institution. World J Surg 35(6):1296-1302. https://doi.org/ 10.1007/s00268-011-1020-z

40. Eslick GD (2009) Epidemiology of esophageal cancer. Gastroenterol Clin N Am 38(1):17-vii. https://doi.org/10.1016/j.gtc.2009.01.008

41. Liu YJ, Fan J, He HH, Zhu SS, Chen QL, Cao RH (2018) Anastomotic leakage after intrathoracic versus cervical oesophagogastric anastomosis for oesophageal carcinoma in Chinese population: a retrospective cohort study. BMJ Open. 8(9):e021025.doi https://doi.org/10.1136/bmjopen-2017-021025

\section{Publisher's Note}

Springer Nature remains neutral with regard to jurisdictional claims in published maps and institutional affiliations.

\section{Submit your manuscript to a SpringerOpen ${ }^{\circ}$ journal and benefit from:}

- Convenient online submission

- Rigorous peer review

- Open access: articles freely available online

- High visibility within the field

- Retaining the copyright to your article

Submit your next manuscript at $>$ springeropen.com 